\title{
In Vivo Whole-Cell Recording of Odor-Evoked Synaptic Transmission in the Rat Olfactory Bulb
}

\author{
Jianhua Cang and Jeffry S. Isaacson \\ Department of Neuroscience, School of Medicine, University of California, San Diego, La Jolla, California 92093-0608
}

\begin{abstract}
One of the first steps in the coding of olfactory information is the transformation of synaptic input to action potential firing in mitral and tufted (M/T) cells of the mammalian olfactory bulb. However, little is known regarding the synaptic mechanisms underlying this process in vivo. In this study, we examined odor-evoked response patterns of $\mathrm{M} / \mathrm{T}$ and granule cells using whole-cell recording in anesthetized, freely breathing rats. We find that odor-evoked excitatory responses in $\mathrm{M} / \mathrm{T}$ cells typically consist of bursts of action potentials coupled to the $\sim 2 \mathrm{~Hz}$ respiration rhythm. Odor-evoked, rhythmic M/T cell excitation is reliable during odor presentation ( $2-4 \mathrm{sec})$; in contrast, both excitatory responses of granule cells and $\mathrm{M} / \mathrm{T}$ cell lateral inhibition adapt quickly after the first respiration cycle in the presence of odorants. We also find that the amplitude and initial slope of odor-evoked synaptic excitation play an important role in regulating the timing of M/T cell spikes. Furthermore, differences in odor concentration alter the shape of odor-evoked excitatory synaptic responses, the latency of $\mathrm{M} / \mathrm{T}$ cell spikes, and the timing of $\mathrm{M} / \mathrm{T}$ cell lateral inhibition.
\end{abstract}

Key words: mitral cell; granule cell; dendrites; spike integration; olfaction; EPSP

\section{Introduction}

Olfactory coding begins with the transduction of odor information into electrical signals by olfactory receptor neurons (ORNs). In mammals, ORNs express only one type of receptor out of a repertoire of $\sim 1000$ (Buck and Axel, 1991). Although an individual ORN expresses only one type of receptor, it can be activated by many different odorants (Malnic et al., 1999; Duchamp-Viret et al., 2000). Axons of ORNs that express the same types of receptors project into the main olfactory bulb and converge to only a few stereotyped glomeruli (Mombaerts et al., 1996). Optical imaging studies have suggested that odor identity and intensity are represented by distributed patterns of activated glomeruli (Rubin and Katz, 1999; Uchida et al., 2000; Belluscio and Katz, 2001; Meister and Bonhoeffer, 2001; Wachowiak and Cohen, 2001; Spors and Grinvald, 2002). Together, these results suggest that a combinatorial and spatial pattern of neuronal activity underlies olfactory coding.

Mitral and tufted $(\mathrm{M} / \mathrm{T})$ cells, the principal cells of the olfactory bulb, receive excitatory input from ORNs on their distal dendrites in glomeruli and convey odor information through their axons to the cortex (Shepherd, 1998). M/T cells also extend lateral dendrites for large distances across the bulb and form reciprocal dendrodendritic synapses with local interneurons, the granule cells (Shepherd, 1998). This reciprocal synaptic arrangement underlies self-inhibition and lateral inhibition of $\mathrm{M} / \mathrm{T}$ cells (Jahr and Nicoll, 1980; Isaacson and Strowbridge, 1998; Schoppa et al., 1998; Chen et al., 2000). Interactions between M/T cells and

Received Nov. 18, 2002; revised Feb. 24, 2003; accepted Feb. 26, 2003.

This work was supported by a Burroughs Wellcome Fund Career Award, a McKnight Scholar Award, and National Institute of Deafness and Other Communication Disorders Grant R01DC04682 (J.S.I.). J.C. is an Aventis Pharmaceuticals Fellow of the Life Sciences Research Foundation. We thank Troy Margrie for an introduction to in vivo recording and Gabe Murphy for comments on this manuscript.

Correspondence should be addressed to Dr. Jeffry S. Isaacson, Department Neuroscience, MC 0608, Basic Science Building, Room 3065, University of California, San Diego School of Medicine, 9500 Gilman Drive, La Jolla, CA 92093-0608. E-mail: jisaacson@ucsd.edu.

Copyright $\odot 2003$ Society for Neuroscience $\quad 0270-6474 / 03 / 234108-09 \$ 15.00 / 0$ local interneurons may contribute to the processing of odor information (Mori et al., 1999).

Temporal patterns of neuronal activity may also play a role in olfaction (Laurent, 1999; Laurent et al., 2001). For example, odors evoke synchronized activity in large ensembles of central olfactory neurons in many species (MacLeod and Laurent, 1996; Kashiwadani et al., 1999; Lei et al., 2002). Furthermore, in insects and zebrafish, olfactory principle cells express complex spiking patterns in response to odorants (MacLeod and Laurent, 1996; Friedrich and Laurent, 2001). This work and theoretical studies (Hopfield, 1995) have implied that the relative timing of M/T cell spikes can provide a mechanism for olfactory coding. In mammals, respiration provides a natural source for temporal patterning in olfaction. The respiration-driven, rhythmic activation of ORNs could provide an oscillatory drive controlling the timing of $\mathrm{M} / \mathrm{T}$ cell spikes. Indeed, studies show that $\mathrm{M} / \mathrm{T}$ firing patterns are correlated with the respiration cycle (Macrides and Chorover, 1972; Chaput and Holley, 1980; Mair and Gesteland, 1982). However, the precise relationship between respiration-coupled ORN synaptic input and M/T spiking has yet to be established.

Many studies have examined odor-evoked responses of olfactory bulb neurons using extracellular unit recording or intracellular microelectrodes (Meredith, 1986; Hamilton and Kauer, 1989; Wellis and Scott, 1990; Imamura et al., 1992). Although these studies have shed light on the nature of odor-evoked firing patterns, much less is known about odor-evoked synaptic transmission. In this study, we use whole-cell patch-clamp recording to examine odor-evoked responses of $\mathrm{M} / \mathrm{T}$ and granule cells in vivo in freely breathing rats.

\section{Materials and Methods}

Animal preparation and odor stimulation. All experiments were performed in vivo on freely breathing rats (Sprague Dawley, postnatal day 12-18) anesthetized with urethane (1.2 gm/ kg, i.p.). Animals were held in a standard stereotaxic apparatus with ear bars. The body temperature was monitored with a rectal thermometer and maintained at $35-37^{\circ} \mathrm{C}$ by 
a feedback-controlled heating pad. Respiration was recorded by measuring chest extension with a piezoelectric strap. A craniotomy was performed to gain access to the dorsal side of the olfactory bulb.

Odors were delivered to the nose through a custom-built olfactometer. Air was filtered (high-efficiency particulate air/charcoal filter) and passed through glass bottles containing filter paper saturated with odorants. Teflon tubing was used for all connections. During experiments, a continuous stream of filtered air was directed to the animal's nose (4.7 $1 / \mathrm{min}$ ). Odor application was regulated by diverting airflow to the odorcontaining bottles via computer-controlled solenoid valves. We used both single and complex compounds as odorants, including aliphatic aldehydes of different change lengths (-CHO), amyl acetate (AA), cinnamon oil (CIN), and peppermint oil (PP). The odor concentration was determined by the $\mathrm{v} / \mathrm{v}$ dilution of odorants in mineral oil, ranging from 1 to $100 \%$.

Physiology. In vivo whole-cell recordings were obtained using the "blind" patch-clamp approach (Blanton et al., 1989; Margrie et al., 2001). Briefly, patch pipettes (5-7 M $\Omega$ ) were filled with a $\mathrm{K}^{+}$-based internal solution containing (in mM): $125 \mathrm{KMeSO}_{4}, 4 \mathrm{KCl}, 10 \mathrm{HEPES}, 10$ phosphocreatine, 3 MgATP, and 0.5 NaGTP, pH 7.3. Electrodes were advanced into the brain in small steps (several micrometers) under positive pressure. When a neuron was encountered, the positive pressure was removed, to achieve a seal resistance of $\geq 1 \mathrm{G} \Omega$. The whole-cell configuration was then achieved by applying additional negative pressure. The membrane potential was recorded with a MultiClamp 700 A amplifier (Axon Instruments, Foster City, CA), filtered at $4 \mathrm{kHz}$, and digitized at 10 $\mathrm{kHz}$ (ITC-18; Instrutech, Port Washington, NY). Series resistance was typically $\sim 40 \mathrm{M} \Omega$ and bridge balance was controlled via the automatic compensation feature of the MultiClamp. Data were acquired using Axograph 4.6 (Axon Instruments). The membrane potential was determined from the value immediately after achieving the whole-cell configuration. In cells that fired spikes spontaneously, the average interspike membrane potential was calculated over several seconds. All reported values have been corrected for an $\sim 10 \mathrm{mV}$ junction potential. Hyperpolarizing and depolarizing currents were injected to determine the input resistance. During experiments, small hyperpolarizing currents $(<500 \mathrm{pA})$ were injected into $\mathrm{M} / \mathrm{T}$ cells to maintain the membrane potentials at rest or below action potential (AP) threshold. The locations of whole-cell recordings were determined relative to the surface of the olfactory bulb from the $z$-axis readout of an MP-285 micromanipulator (Sutter Instruments, Novato, CA).

Statistical analysis. Respiration and membrane potential responses were analyzed using Axograph or routines written in IGOR Pro (WaveMetrics, Lake Oswego, OR). To analyze the temporal relationship between spiking and subthreshold EPSPs in M/T cells, we aligned all odorevoked responses to the onset of inspiration during each respiration cycle. Individual respiration cycles were detected with Axograph using a sliding template derived from the respiration pattern of each experiment. The template is slid along the respiration trace, one point at a time, and is optimally scaled and offset to fit the data at each position. A detection criterion related to the signal-to-noise ratio of the detected event is calculated from the goodness-of-fit between the scaled template and the data. The methods of detection and alignment of respiration cycles are identical to those used to analyze spontaneous synaptic events (Clements and Bekkers, 1997). For subthreshold responses, 10-40 events were averaged to determine the underlying EPSP for each condition. The peak amplitude of the average EPSP was determined by averaging $20 \mathrm{msec}$ around the EPSP peak. The EPSP slope was determined from a line fit to the rising phase of the EPSP. The absolute time of APs during each respiration cycle was used to construct raster plots and peristimulus time histograms (PSTHs). To combine results from different cells, we used the time point at which the averaged subthreshold EPSP reached $10 \%$ of its peak amplitude during the respiration cycle as time 0 . M/T cell IPSP amplitudes were measured from aligned and averaged traces in a manner similar to that used for EPSPs. Individual spontaneous EPSCs and EPSPs in granule cells were also detected and analyzed using the sliding template approach in Axograph.

All data are reported as means \pm SEM. Significance was determined

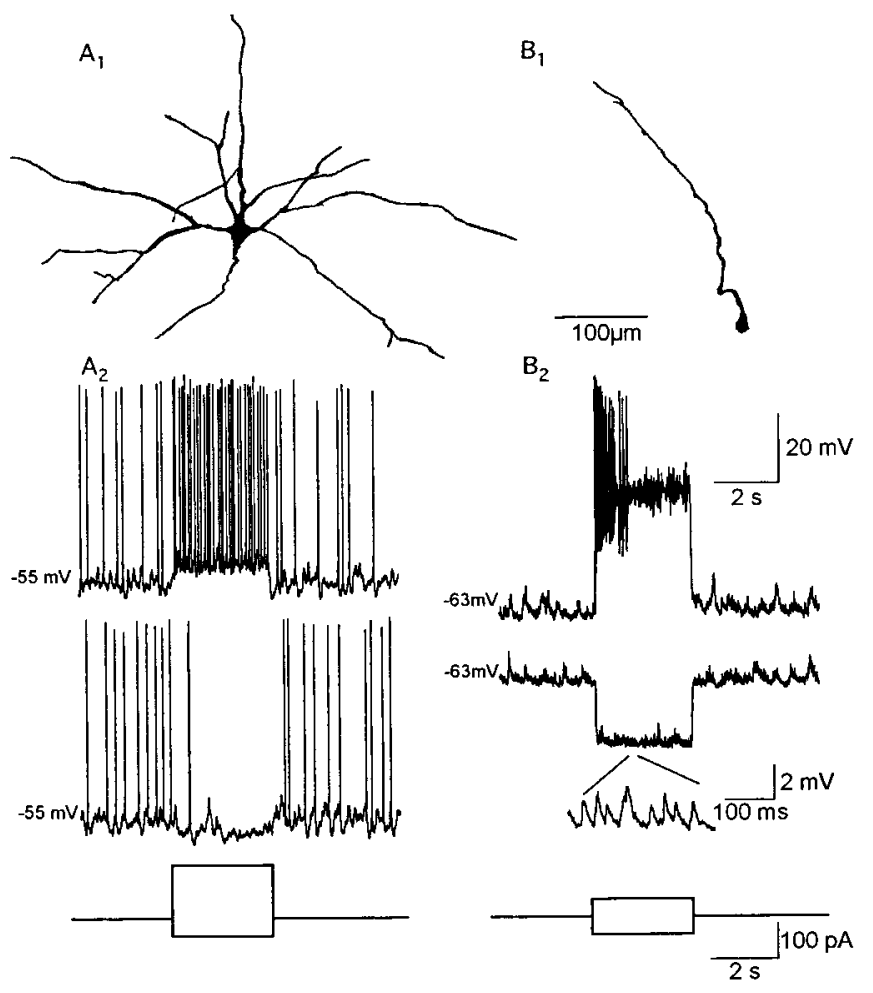

Figure 1. Identification of $\mathrm{M} / \mathrm{T}$ cells. In vivo whole-cell recordings of a mitral cell $(A)$ and a granule cell $(B)$ and their morphology. The resting membrane potentials were approximately -55 and $-65 \mathrm{mV}$ for the mitral and granule cells, respectively. M/T cells could be discerned by their extensive lateral dendrites $\left(A_{1}\right)$, whereas granule cells had a small soma $\left(B_{1}\right)$. The glomerular dendritic tuft of this mitral cell was not recovered. The responses to current injection illustrate the fact that mitral cells $\left(A_{2}\right)$ have a lower input resistance than granule cells $\left(B_{2}\right)$. Also, individual fast spontaneous EPSPs are typically observed in granule cells (inset) but not M/T cells.

using Kolmogorov-Smirnov statistics for the data of individual cells and the two-tailed paired $t$ test for comparison between two groups.

\section{Results}

\section{Identification of olfactory bulb neurons}

Olfactory bulb neurons were studied using whole-cell patchclamp recording in urethane-anesthetized, freely breathing rats. There are two main classes of neurons in the mammalian olfactory bulb: principal $\mathrm{M} / \mathrm{T}$ cells and local interneurons (granule cells). These cells were distinguished based on their distance from the bulb surface (200-300 $\mu \mathrm{m}$ for M/T cells, $>300 \mu \mathrm{m}$ for granule cells) and electrophysiological characteristics (Fig. 1). The average membrane potential of M/T cells was $-56 \pm 1.2 \mathrm{mV}$ (range, -65 to $-47 \mathrm{mV} ; n=22$ ), more depolarized than that of granule cells ( $-63 \pm 1.5 \mathrm{mV}$; range, -76 to $-54 \mathrm{mV} ; n=21$ ). The input resistance of $\mathrm{M} / \mathrm{T}$ cells was significantly less than that of granule cells: $115 \pm 16$ compared with $332 \pm 38 \mathrm{M} \Omega$. Furthermore, as reported in previous studies (Wellis and Scott, 1990; Luo and Katz, 2001), granule cells exhibited a high frequency of spontaneous EPSPs (Fig. $1 B$ ). These criteria of identifying M/T and granule cells were further confirmed by biocytin staining of four mitral cells and three granule cells (Fig. 1). M/T and granule cells also displayed different degrees of spontaneous activity. Among the 22 putative $\mathrm{M} / \mathrm{T}$ cells, 10 were spontaneously active and firing spikes at a rate of $2.8 \pm 0.7 \mathrm{~Hz}$. In contrast, the majority of granule cells did not spontaneously fire APs at rest ( $n=14$ of 21), or did so at very low frequency $(<0.5 \mathrm{~Hz} ; n=6$ of 21$)$. 

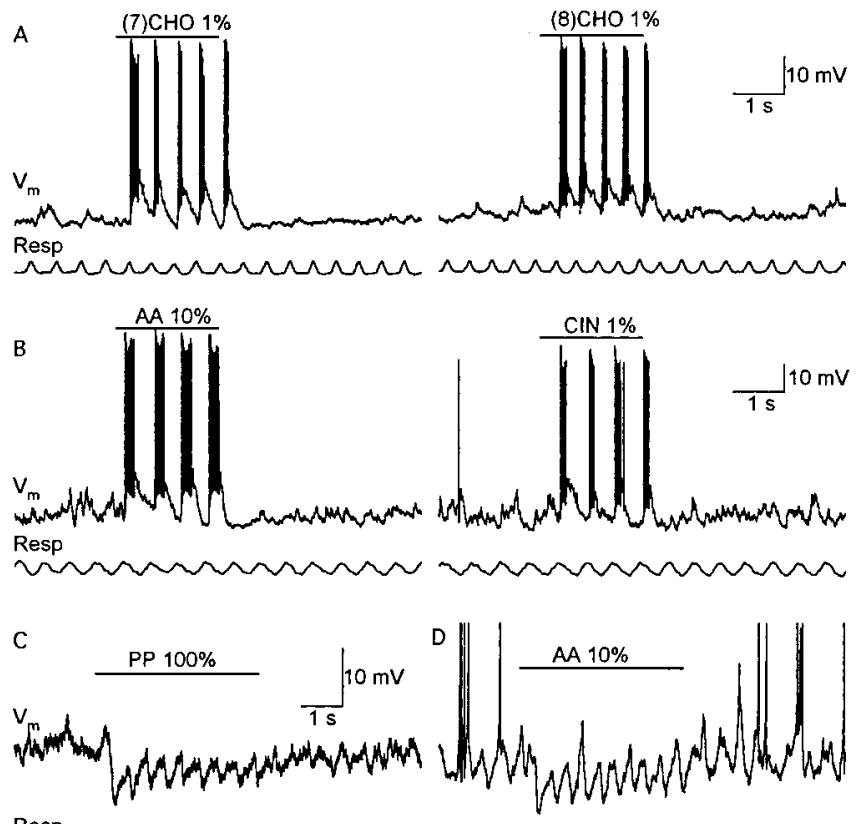

Resp

Figure 2. Odors evoke respiration-coupled activity in $\mathrm{M} / \mathrm{T}$ cells. In each panel, the membrane potential is shown by the top trace and the bottom trace is the simultaneously recorded respiratory activity. Horizontal bars indicate the duration of odor application. For the cell in $A$, both $1 \%$ heptanal $[(7) \mathrm{CHO}]$ and octanal $[(8) \mathrm{CHO}]$ elicited bursts of respiration-coupled APs during odor stimulation. For the cell in B, 10\% AA and 1\% CIN elicited bursts of APs coupled to respiration. C, "Pure" inhibitory response of an $\mathrm{M} / \mathrm{T}$ cell to $100 \%$ PP. D, Inhibitory response of another $\mathrm{M} / \mathrm{T}$ cell to $10 \%$ AA. The APs are truncated, and scale bars in C also apply to $D$.

\section{Odor-evoked responses of $\mathrm{M} / \mathrm{T}$ cells}

Individual odorants could elicit a variety of responses in different M/T cells (Wellis et al., 1989; Luo and Katz, 2001; Margrie et al., 2001). For example, the same odorant could cause excitation in some M/T cells and inhibition in others (Fig. 2). Previous studies have reported that odors can also evoke complex patterns of $\mathrm{M} / \mathrm{T}$ cell activity, presumably because of a mixture of excitation and inhibition (Harrison and Scott, 1986; Hamilton and Kauer, 1989; Wellis et al., 1989; Laurent, 1999). We also found M/T cells that responded to odors with prolonged excitation or an apparent mixture of excitation and inhibition (data not shown). However, in the majority of M/T cells ( 22 of 32 in current- or voltage-clamp recordings) odor-evoked responses consisted of relatively simple patterns dominated by either excitation or inhibition. We focused on M/T cells with such relatively simple patterns for additional analyses to study the relationship between excitatory synaptic input and AP output of M/T cells. In our study, the majority of excitatory responses were bursts of APs coupled to the $\sim 2 \mathrm{~Hz}$ respiration rhythm (Fig. 2). The excitatory responses of individual M/T cells to different types of odors could be remarkably similar (Fig. 2). In addition, different M/T cells (which receive inputs from different glomeruli) could show similar types of responses to the same odorants. Thus, we took advantage of this feature of M/T cells to pool responses from different cells and different odors in our analyses.

To examine the input-output relationship of $\mathrm{M} / \mathrm{T}$ cells, we applied odorants while injecting hyperpolarizing current to bring the membrane potential to $-70 \mathrm{mV}$, close to the reversal potential of $\mathrm{GABA}_{\mathrm{A}}$-mediated inhibition under our conditions ( $4 \mathrm{~mm}$ internal $\mathrm{Cl}^{-}$). $\mathrm{M} / \mathrm{T}$ cells that responded to odor stimulation with bursts of APs displayed subthreshold membrane potential depo-
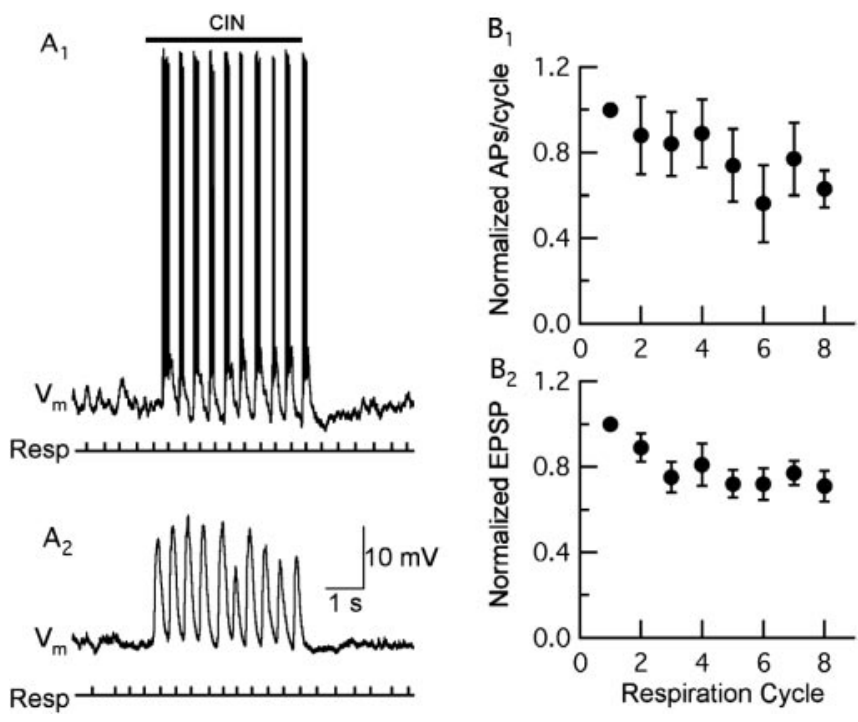

Figure 3. Odors evoke $M / T$ cell excitation that is reliable across respiration cycles. $A_{1}$, The spiking response of an M/T cell to CIN. The stimulation duration was $4 \mathrm{sec}$, indicated by the horizontal line. $A_{2}$, Subthreshold response of the same $\mathrm{M} / \mathrm{T}$ cell. When hyperpolarized, the $\mathrm{M} / \mathrm{T}$ cell displayed rhythmic summated EPSPs of $\sim 10 \mathrm{mV}$ during odor stimulation. In both $A_{1}$ and $A_{2}$, the onset of inspiration is indicated by vertical lines in the respiration signal (Resp). Traces in $A_{1}$ and $A_{2}$ are aligned with respect to the time of odor application. The different latencies to response onset reflect the fact that the first respiration cycle in the presence of odor occurs earlier in $A_{2}$ compared with $A_{1}$. The mean AP number $\left(B_{1}\right)$ and EPSP amplitude $\left(B_{2}\right)$ during each respiration cycle normalized to those of the first cycle after odor onset ( $n=8$ cells).

larizations that were clearly correlated with the respiration cycle. On average, odor-evoked depolarizations had rise times (10$90 \%$ of peak amplitude) of $100 \pm 13 \mathrm{msec}$, and decayed with a time constant of $196 \pm 29 \mathrm{msec}(n=7)$. The slow kinetics of these excitatory responses are not attributable solely to the passive membrane properties of $\mathrm{M} / \mathrm{T}$ cells, because the membrane time constants of the same M/T cells were much faster (22 $\pm 4 \mathrm{msec}$ ). We consider these excitatory responses to reflect summating EPSPs from the ORNs. In the cells studied, the AP numbers per cycle ranged from 1 to 18; EPSP amplitudes ranged from 2 to 20 $\mathrm{mV}$. We next examined whether the odor-evoked responses displayed temporal changes during the course of odor presentation ( 2 or $4 \mathrm{sec}$ ). The number of APs (Fig. $3 B_{1}$ ) and EPSP amplitudes (Fig. $3 B_{2}$ ) during each respiration cycle were normalized to those of the first cycle after odor onset for each cell. Although EPSP amplitude and AP number tended to decrease slightly from the first to the last during odor stimulation, the decline was not significant ( $p=0.54$ for AP numbers; 0.10 for EPSP amplitude; $n=8$; one-way ANOVA). Therefore, we treated each cycle of respiration-driven activity as an independent event in our additional analyses.

It has been suggested that spike timing may be an important factor in coding odor information (Hopfield, 1995; Laurent et al., 2001). We next examined when APs occur in relation to the time course of the underlying EPSP during each respiration cycle. M/T cells typically started firing soon after the onset of odor-evoked depolarization (Fig. $4 A_{1}$ ). In some cycles, AP firing was not maintained, although the membrane potential was suprathreshold (Fig. $4 A_{1}$ ). For additional investigation, we aligned both odorevoked APs and subthreshold EPSPs to the respiration cycle. We compared the PSTH and averaged subthreshold EPSPs in the same cells (Fig. $4 A_{2}$ ). An example of this comparison for one cell is shown in Figure $4 A$, and a summary of the results from several cells is shown in Figure $4 B(n=5)$. We found that the majority of 

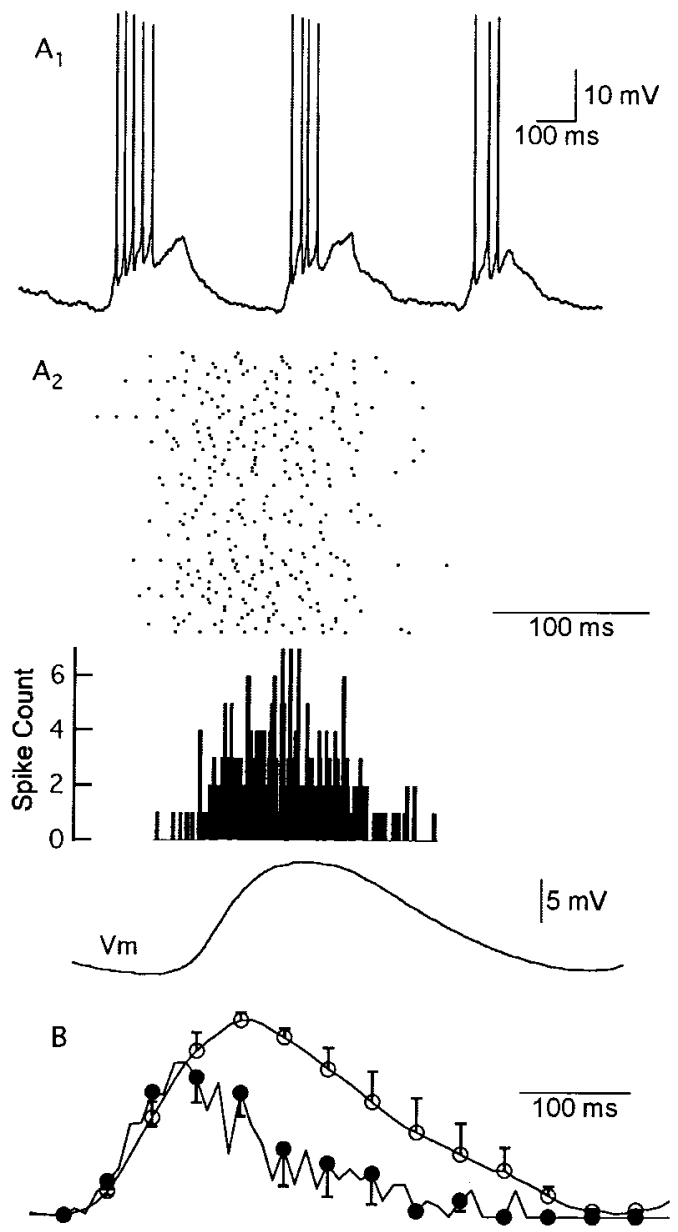

Figure 4. Odor-evoked $M / T$ cell spikes occur preferentially during the rising phase of the EPSP. $A_{1}$, Firing patterns of an $\mathrm{M} / \mathrm{T}$ cell during odor application. Three consecutive respiratory cycles in the presence of $100 \%$ CIN are shown. $A_{2}$, The raster plot of spike times, PSTH of odor-evoked APs, and mean odor-evoked EPSP of the M/T cell in $A_{1}$ were aligned to the time of inspiration onset and shown on the same time scale. Top, A raster plot of 79 cycles of odorevoked APs. No systematic change of the AP number or timing was observed. Middle, The PSTH of the 79 cycles of APs was constructed with a bin width of $5 \mathrm{msec}$. Bottom, Averaged EPSP of the subthreshold responses at $-70 \mathrm{mV}$ aligned to the onset of inspiration; $65 \%$ of the APs in this cell occurred before the peak of the EPSP. B, Group data of the firing probability (filled circles) and subthreshold EPSPs (open circles). For each M/T cell, the firing probability was calculated from the probability density function (PDF) of spike times. The PDF and EPSP were normalized to their peak amplitudes and averaged for five cells. For clarity, only one of every four error bars are plotted.

APs occurred during the rising phase of the EPSP; on average, $77 \pm 6 \%$ of the evoked APs occurred before the EPSP peak. In terms of information coding, these results suggest that the most salient features of the odor stimulus are contained in the rising phase of the EPSP.

Given the relative importance of the EPSP rising phase on AP initiation, we next examined the timing of the first APs within odor-evoked responses of each respiration cycle. As before, odorevoked responses were aligned to the respiration cycle. However, response onset in reference to the respiration signal was variable between cells. To compensate for this variability, we used the time when the averaged subthreshold EPSP of each individual cell reached $10 \%$ of its peak during the respiration cycle (10\% EPSP onset) as our time reference point (time 0 ). We found that the first AP latency was negatively correlated with the number of APs evoked during each respiration cycle (Fig. 5B). For all cells exam-
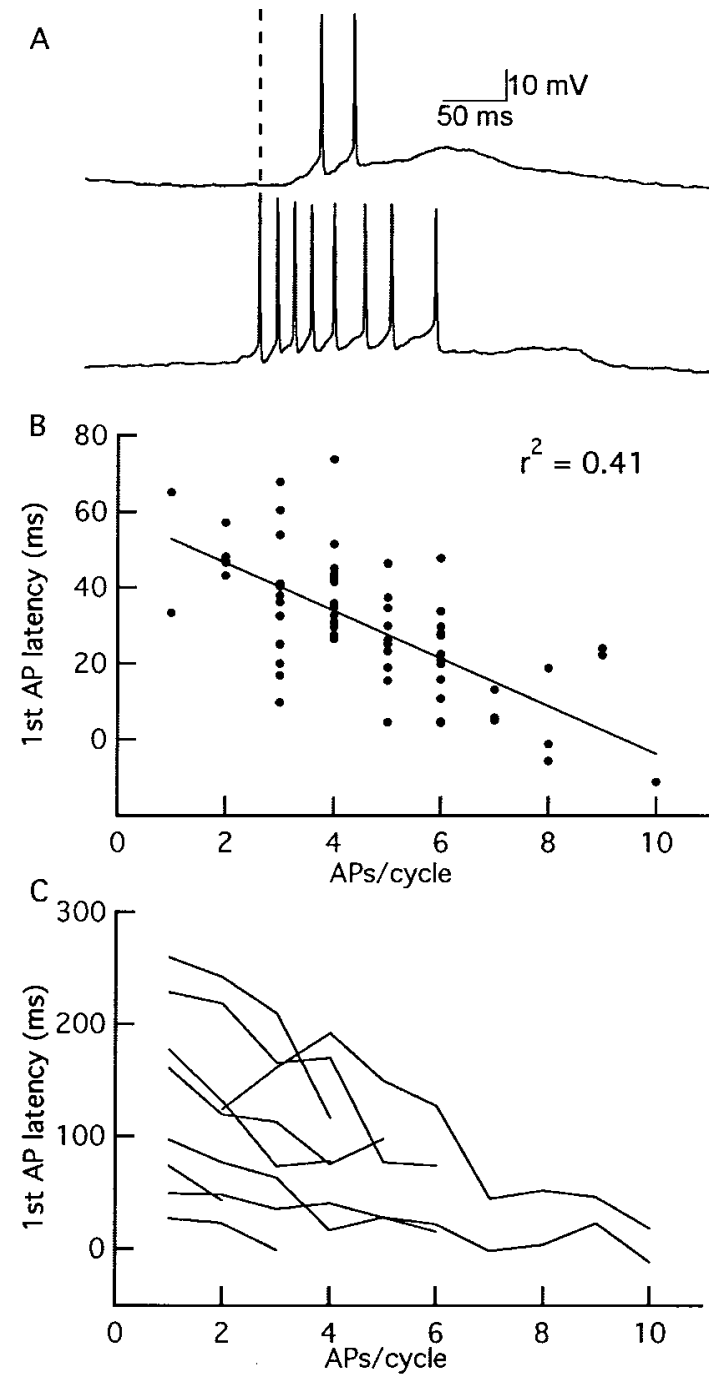

Figure 5. Odor-evoked AP latency and spike number are negatively correlated during respiration cycles. $A$, Membrane potential of an $\mathrm{M} / \mathrm{T}$ cell during two respiration cycles in response to $100 \%$ CIN. The first AP latency, determined by the delay from the $10 \%$ onset of the averaged EPSP (indicated by the vertical dashed line; see Materials and Methods), is smaller for the response with eight APs than that with two APs. B, Plot of first AP latency versus AP number of one M/T cell. First AP latency and the number of APs in each cycle are negatively correlated $\left(r^{2}=0.41 ; p<0.001\right)$. C, Group data showing the results for nine cells. Each line represents one cell and shows the mean of the first AP latency plotted against the AP number in each respiration cycle. For clarity, error bars are omitted.

ined $(n=9)$, the latency of the first AP in each respiration cycle decreased when the number of odor-evoked APs increased (Fig. $5 C)$. The relationship between spike number and first AP latency suggests that the respiration-driven, membrane potential oscillations provide a mechanism to control AP timing.

Previous studies have suggested that the magnitude of M/T output is graded with respect to odor concentration (Kauer, 1974; Mair, 1982; Harrison and Scott, 1986). However, the temporal pattern of $\mathrm{M} / \mathrm{T}$ spikes can also vary with changes in odor concentration (Harrison and Scott, 1986). The relationship we observe between the first AP latency and number of APs per respiration cycle also suggests a possible role for spike timing in coding odor intensity. To address this issue, we next examined how $\mathrm{M} / \mathrm{T}$ cells respond to changes in odor intensity. Odors were applied at two concentrations: a "low" concentration that clearly generated an excitatory response and a concentration that was 10 

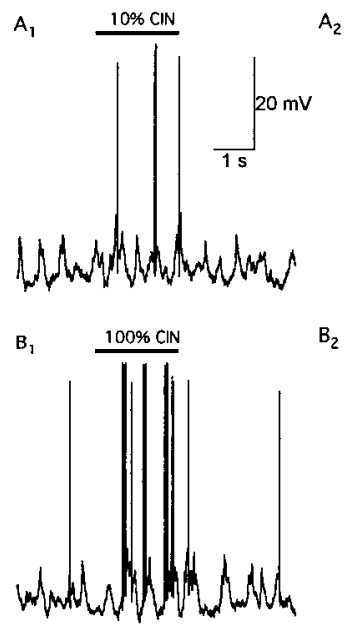
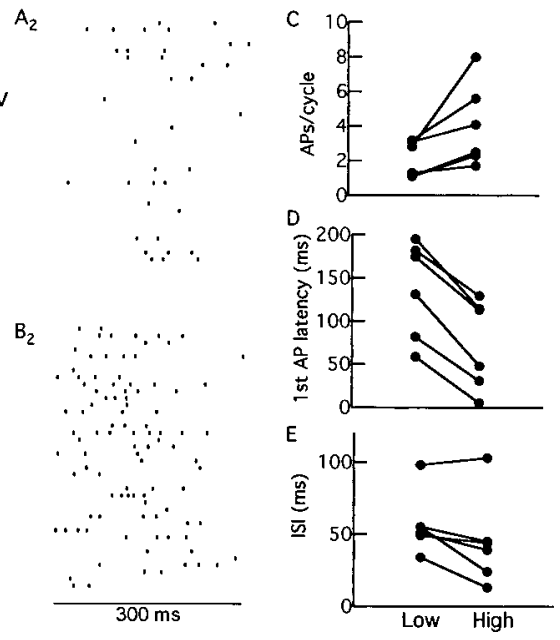

Figure 6. Odor-evoked $\mathrm{M} / \mathrm{T}$ cell spiking is dependent on odor intensity. $A$, Responses of an $\mathrm{M} / \mathrm{T}$ cell to $10 \%$ CIN. $A_{1}$, Single trial responses in the presence of odor. $A_{2}$, Raster plots of 40 consecutive cycles from multiple trials. $B$, Responses of the same M/T cell to $100 \%$ CIN. Increasing odor intensity caused the M/T cell to respond with more APs during each respiration cycle, and the first APs occurred earlier in each cycle. The group data of average APs per cycle $(C)$, first AP latency $(D)$, and ISI $(E)$ are shown for each cell in response to high and low odor intensity. Each line connects the two points representing the averages of each cell at the two conditions.

times stronger ("high"). One example comparing spiking responses evoked by different odor intensities is shown in Figure 6. Single trials and raster plots of APs evoked during each respiration cycle are shown for responses to 10 and 100\% CIN (Fig. $6 A, B)$. Overall, increasing odor intensity led to two marked changes in response: cells responded with more APs and the APs occurred earlier within each cycle (Fig. $6 C, D)(n=6)$. Here, the $10 \%$ onset time of the EPSP evoked by the stronger odor for each cell was used as time 0 to compare the absolute change of first AP latency. On average, the number of APs increased from $2.1 \pm 0.4$ per cycle for our low odor concentrations to $4.0 \pm 1.0$ per cycle during stronger stimulation ( $p<0.05$; paired $t$ test). Under these conditions, the first AP latency decreased from $137 \pm 23$ to $73 \pm$ $21 \mathrm{msec}$ ( $p<0.001$; paired $t$ test). We then considered whether the firing frequency within each respiration cycle was sensitive to changes in odor intensity. To address this question, we measured the interspike intervals (ISIs) within each respiration cycle and averaged these values for each condition. In contrast to the marked effect on first spike latency, the ISI decreased significantly for only a fraction of the cells ( $n=3$ of 6 ; Kolmogorov-Smirnov test). On average, the decrease of ISI, from $57 \pm 8.8 \mathrm{msec}$ for weaker stimuli to $45 \pm 12.7 \mathrm{msec}$ for stronger stimuli, was not significant ( $p=0.07$; paired $t$ test). Odor-evoked AP firing frequencies did not reach the rates obtained in the same cells in response to strong depolarizing current injection $(\sim 50 \mathrm{~Hz})$. Therefore, the relatively modest intensity-dependent changes in $\mathrm{M} / \mathrm{T}$ cell ISIs were not attributable to saturation of the firing rate.

We next investigated the underlying synaptic mechanisms contributing to odor intensity coding in M/T cells. Although the peak amplitude and initial slope of odor-evoked EPSPs varied for different cells and different odors, both of these parameters were sensitive to changes in odor intensity (Fig. 7). On average, the EPSP peak amplitude increased significantly for stronger odors (low concentration, $3.4 \pm 1.0 \mathrm{mV}$; high, $7.4 \pm 1.7 \mathrm{mV} ; p<0.01$; paired $t$ test; $n=6$ ). The EPSP initial slope increased to a similar degree (low concentration, $16 \pm 4.0 \mathrm{mV} / \mathrm{sec}$; high, $41 \pm 9.3 \mathrm{mV} /$ sec; $p<0.05$; paired $t$ test; $n=6$ ). The EPSP latency responded
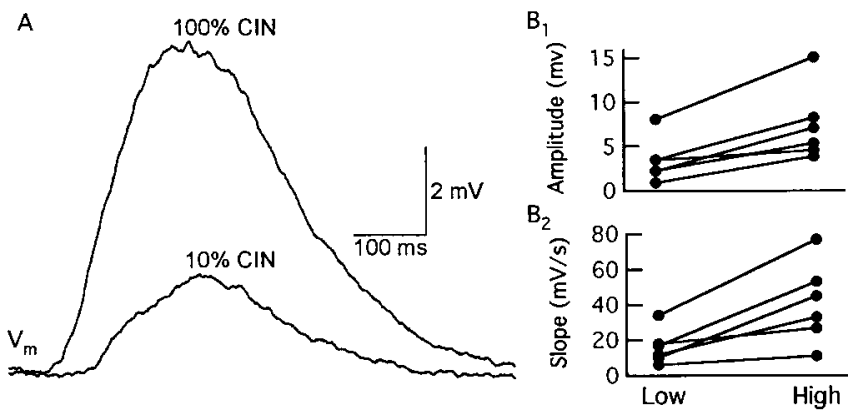

Figure 7. The amplitude and slope of odor-evoked M/T cell EPSPs are governed by odor intensity. $A$, Superimposed average EPSPs evoked by 10 and $100 \%$ CIN in the same M/T cell. $B_{1}$, Summary data of odor intensity-dependent changes in EPSP amplitude. Each line represents the responses of one cell under the two conditions. $B_{2}$, Summary data of the effect of changes in odor intensity on EPSP initial slope.

more variably to changes in odor intensity. Although increasing odor intensity decreased the EPSP latency in some M/T cells (compare Fig. 7A), on average, the latency did not change significantly $(n=6 ; p=0.42)$. Together, these results indicate that changes in odor intensity lead to changes in both the amplitude and the initial time course of odor-evoked EPSPs.

Intensity-dependent changes in the latency of $\mathrm{M} / \mathrm{T}$ cell spikes would contribute to the temporal pattern of olfactory information relayed to the cortex. In addition, changes in $\mathrm{M} / \mathrm{T}$ cell activity may influence local processing within the olfactory bulb attributable to lateral interactions between M/T cells. Reciprocal dendrodendritic inhibition between $\mathrm{M} / \mathrm{T}$ and granule cells has been suggested to play an important role in odor coding (Mori et al., 1999). We next examined whether changes in odor intensity affected local processing by studying a subset of $\mathrm{M} / \mathrm{T}$ cells that displayed inhibitory odor-evoked responses at their resting membrane potentials.

Like cells that were excited by odors, some M/T cells showed clear odor-evoked IPSPs that were coupled to the respiratory rhythm (Figs. 2C,D, 8). In contrast to M/T cell EPSPs, the peak amplitude of rhythmic, odor-evoked IPSPs did change markedly over the course of odor application. The amplitudes of odorevoked IPSPs were larger during the first respiration cycle compared with subsequent cycles in the presence of odor (Fig. 8A) ( $n=6 ; p<0.01$, one-way ANOVA; $p<0.01$, Dunnett's test). Although odor-evoked EPSPs did not show a dramatic shift of onset latency, increasing odor intensity decreased the latency of IPSPs in all cells examined (Fig. $8 B)(n=4)$. Given the circuitry of the olfactory bulb (Shepherd, 1998), these IPSPs must be attributable to lateral inhibition initiated by other $\mathrm{M} / \mathrm{T}$ cells that were themselves excited by the odorant. The change in IPSP onset in response to increasing odor intensity is most likely explained by the latency shift in spike timing we observed in M/T cells excited by odorants. Together, these findings suggest that the local synaptic processing attributable to lateral inhibition in the olfactory bulb is dynamic: lateral inhibition is strongest during the first respiration cycle in the presence of an odor and the latencies of IPSPs are also sensitive to differences in odor intensity.

\section{Odor-evoked responses of granule cells}

For additional exploration of how odor information is processed in local circuits of the olfactory bulb, we examined the spontaneous and evoked activity of granule cells. Although granule cells typically received a high-frequency barrage of EPSPs $(35 \pm 8.4$ 

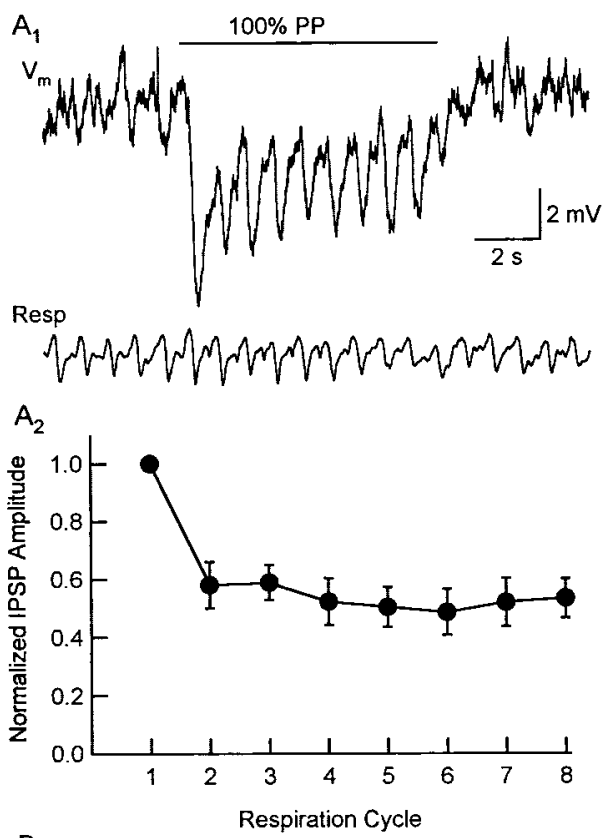

B

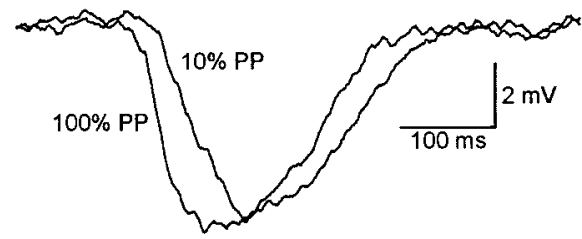

Figure 8. Odor-evoked M/T cell inhibition. $A_{1}$, Inhibitory response of an $\mathrm{M} / \mathrm{T}$ cell to $100 \% \mathrm{PP}$. Top, Membrane potential. Bottom, Respiration signal. The horizontal line indicates the duration of odor stimulation ( $4 \mathrm{sec})$. $A_{2}$, Normalized IPSP amplitudes were plotted against respiration cycle $(n=6) . B$, The odor-evoked IPSPs of another M/T cell were aligned to the inspiration onset of each respiration cycle and averaged. The average IPSP in response to strong odor stimulation (100\% PP) occurs earlier than that evoked by weaker odor stimulation (10\% PP).

$\mathrm{Hz} ; n=6$ ), the majority of granule cells did not spontaneously fire APs. We studied the spontaneous synaptic events in both current- and voltage-clamp configurations (Fig. 9). In cells recorded in current-clamp mode at $V_{\text {rest }}$, spontaneous EPSPs had an average amplitude of $3.5 \pm 0.7 \mathrm{mV}$ and average rise times and decay time constants of $2.5 \pm 0.8$ and $13.6 \pm 3.8 \mathrm{msec}$, respectively ( $n=8$ cells). In voltage-clamp recordings $\left(V_{\mathrm{m}}=-80 \mathrm{mV}\right)$, spontaneous EPSCs had an average amplitude of $38 \pm 10 \mathrm{pA}$ and rise times and decay time constants of $0.95 \pm 0.1$ and $3.6 \pm 0.5$ msec, respectively ( $n=5$ cells). The decay time constants of granule cell EPSCs in this study are somewhat slower than those recorded previously in olfactory bulb slices (Isaacson, 2001), most likely because of the larger access resistance encountered with in vivo recording. Despite receiving a relatively high frequency of spontaneous EPSPs, the low rate of spontaneous granule cell APs presumably reflects the relatively rapid kinetics of individual synaptic events as well as the hyperpolarized resting potential of granule cells (approximately $-65 \mathrm{mV}$ ).

Similar to $\mathrm{M} / \mathrm{T}$ cells, granule cells displayed rhythmic depolarizations that were coupled to the respiration rhythm in response to odor stimulation (Fig. 10A). In contrast to odorevoked EPSPs in M/T cells, granule cell responses adapted quickly after the first respiration cycle. On average, the response amplitude during the second cycle was only $64.2 \pm$ $7.9 \%$ of the first cycle (Fig. $10 B)(n=10 ; p<0.05$, one-way ANOVA; $p<0.01$, Dunnett's test). We found that the ampli-

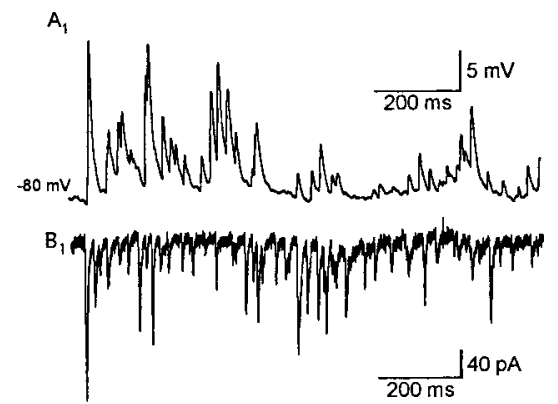

$\mathrm{A}_{2}$
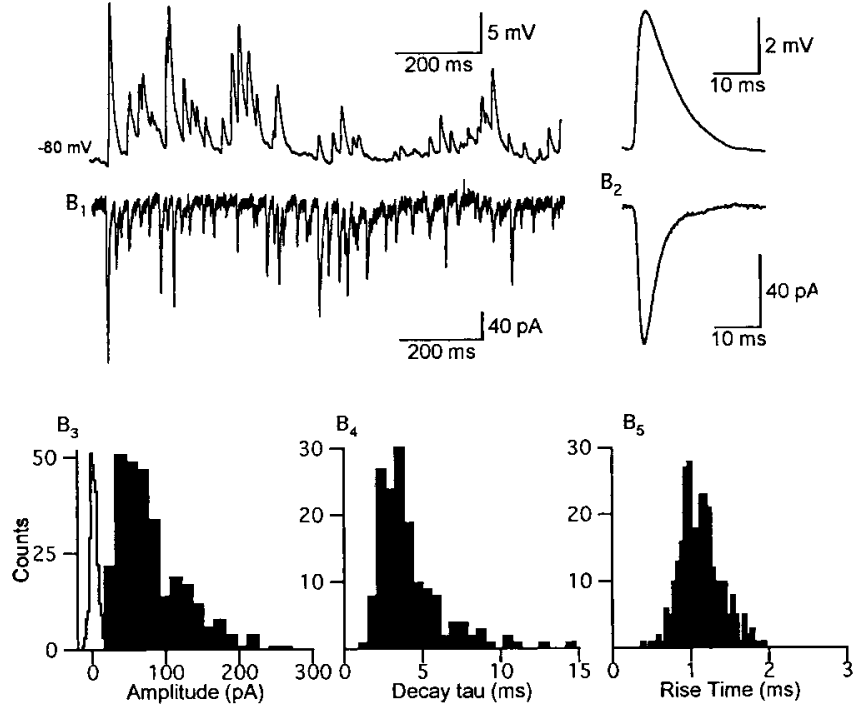

Figure 9. Spontaneous EPSPs and EPSCs in granule cells. A, Current-clamp recording of a granule cell. $A_{1}$, A short record of membrane potential illustrating that granule cells receive a high frequency of EPSPS. $A_{2}$, Average of individual EPSPs. $B$, Voltage-clamp recording $\left(V_{\mathrm{m}}=\right.$ $-80 \mathrm{mV})$ of the same granule cell $\left(B_{1}\right)$ and average of the EPSCs $\left(B_{2}\right)$. Histograms of spontaneous EPSC peak amplitudes (filled bars) and background noise (open bars) $\left(B_{3}\right)$, decay time constants $\left(B_{4}\right)$, and rise times $\left(B_{5}\right)$ are shown.
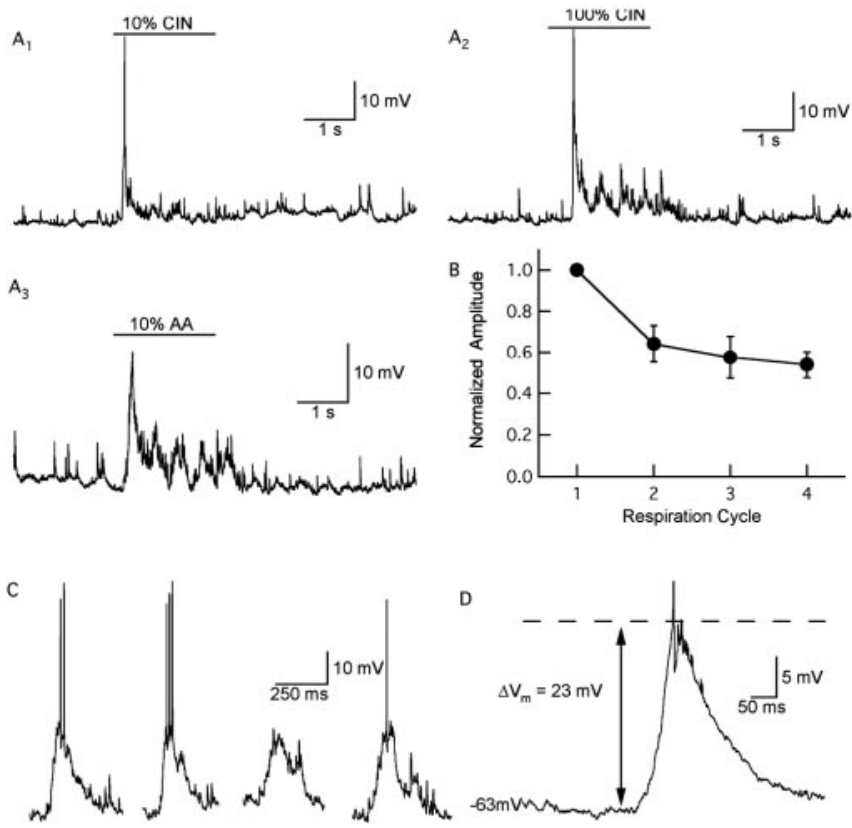

D

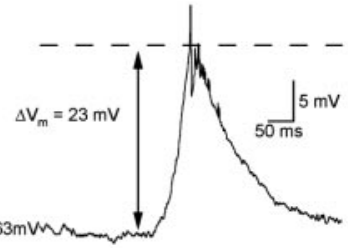

Figure 10. Odor-evoked responses of granule cells. $A$, Responses of a single granule cell to $10 \%\left(A_{1}\right)$ and $100 \%\left(A_{2}\right)$ CIN. The same granule cell also responded to $10 \% \mathrm{AA}\left(A_{3}\right)$. Horizontal bars indicate the duration of odor application. APs in $A_{1}$ and $A_{2}$ are truncated to better illustrate subthreshold EPSPS. $B$, Amplitudes of granule cell responses during each respiration cycle normalized to that of the first cycle after odor onset $(n=10)$. Response amplitudes in the second, third, and fourth cycles are significantly smaller than that during the first cycle. C, Four selected cycles of odor-evoked ( $10 \% \mathrm{AA}$ ) responses of another granule cell. D, Spike-triggered average of odor-evoked responses of the same cell in C. On average, this granule cell required a depolarization of $23 \mathrm{mV}$ to reach the AP threshold.

tudes of rhythmic, odor-evoked EPSPs in granule cells were also enhanced when the odor concentration was increased (Fig. 10A); however, we did not further explore intensitydependent responses of granule cells. 
Granule cells typically required high-amplitude, summated EPSPs to reach the AP threshold during odor-evoked activation (Fig. 10D). We used spike-triggered averaging to examine the responses underlying odor-evoked granule cell firing. Odorevoked rhythmic responses (7-30 per cell) were aligned to the rising phase of the first AP in each event. Even when odor-evoked responses reached the AP threshold, the number of spikes evoked per respiration cycle was generally low $(2.1 \pm 0.5 ; n=6$ cells $)$. Visual inspection of the inflection point preceding the AP upstroke was used to estimate the odor-evoked AP threshold in granule cells. The difference between the resting membrane potential and the AP threshold in these cells averaged $15.8 \pm 1.9 \mathrm{mV}$ $(n=6)$. These spike-triggered average data indicate that granule cells require strong, relatively synchronous excitatory input to reach AP threshold. Although we cannot exclude the possibility that some granule cell EPSPs arise from centrifugal inputs, the simplest interpretation of these results is that granule cells require strong input from $\mathrm{M} / \mathrm{T}$ cells to reach AP threshold in response to odorants.

\section{Discussion}

In this study, we used whole-cell recording to characterize odorevoked responses of $\mathrm{M} / \mathrm{T}$ and granule cells in anesthetized, freely breathing rats. We found that odor-evoked excitatory responses of the majority of M/T cells consisted of EPSPs and bursts of APs that were coupled to the $\sim 2 \mathrm{~Hz}$ respiratory cycle. In contrast, the odor-evoked responses of granule cells had few APs and adapted quickly after the first respiration cycle. Furthermore, granule cells required strong, odor-evoked excitatory input to reach AP threshold. For M/T cells, the majority of APs occurred during the rising phase of summated EPSPs, and the latency of the first APs during each respiration cycle was negatively correlated with the number of evoked APs. M/T cells responded to stronger odorant stimulation with more APs during each cycle and a shorter latency to the time of the first AP. Odor-evoked M/T cell lateral inhibition adapted strongly after the first respiration cycle, and the latency of lateral inhibition decreased as the odor intensity increased.

\section{Odor-evoked responses of $\mathrm{M} / \mathrm{T}$ cells}

Previous studies have revealed that odors can evoke both simple and complex activity patterns in olfactory bulb neurons. In this study, we show that odorants can evoke responses in M/T cells that are dominated by synaptic excitation or inhibition driven by the respiration rhythm. In rodents, extracellular unit recordings have revealed that odor-evoked $\mathrm{M} / \mathrm{T}$ cell spikes are generally coupled to the respiratory rhythm (Macrides and Chorover, 1972; Chaput and Holley, 1980; Mair and Gesteland, 1982). However, studies of the relationship between $\mathrm{M} / \mathrm{T}$ activity and respiration have typically sought to determine the source of the rhythm, i.e., whether it is purely peripheral (nasal) or modulated by central inputs (Onoda and Mori, 1980; Ravel et al., 1987; Sobel and Tank, 1993). These studies indicate primarily that periodic sampling of odors by ORNs during inspiration underlies rhythmic M/T cell spiking.

We find that $\mathrm{M} / \mathrm{T}$ cells respond to ORN input in a manner that is generally consistent throughout the time course of odor stimulation. On average, the number of evoked spikes per respiration cycle did not change significantly during the course of odor presentation. The lack of adaptation in $\mathrm{M} / \mathrm{T}$ cell firing is consistent with the relatively small changes we see in ORN-mediated EPSPs in $\mathrm{M} / \mathrm{T}$ cells. Individual ORNs show adaptation during prolonged odor exposure (Zufall and Leinders-Zufall, 2000). How- ever, our findings using 2-4 sec of odor application are consistent with previous results showing a lack of adaptation in the electroolfactogram in freely breathing rats (Chaput, 2000). Presumably, the periodic exposure to odorants during respiration serves to minimize ORN adaptation.

We also find that odor-evoked IPSPs in M/T cells and EPSPs in granule cells are dynamically regulated over the course of odor presentation. Granule cell excitation is maximal during the first respiration cycle in the presence of odor and is $\sim 40 \%$ weaker over subsequent cycles. M/T cell lateral inhibition showed a virtually identical time course. Dendrodendritic reciprocal synapses formed between $\mathrm{M} / \mathrm{T}$ and granule cells are likely to underlie the parallel temporal responses of the two cell types. What underlies the adaptation of granule cell excitation and M/T cell lateral inhibition? One possibility is that GABAergic feedback inhibition of the M/T cells mediating lateral inhibition leads to a reduction in AP propagation in their lateral dendrites (Xiong and Chen, 2002). Alternatively, the requirement in granule cells for strong temporal summation of rapid EPSPs to reach AP threshold may play a role. Our results suggest that granule cell spiking would require convergent and relatively synchronous input from an ensemble of active M/T cells. Thus, another possibility to account for adaptation in granule cells is that the relative timing of APs in ensembles of activated M/T cells becomes "desynchronized" during the course of odor presentation (Friedrich and Laurent, 2001; Laurent et al., 2001).

\section{Effect of odor intensity on $\mathrm{M} / \mathrm{T}$ cell responses}

We find that the number of spikes during each respiration cycle is closely correlated with the first AP latency in M/T cells. The simple correlation between spike count and first AP latency suggests that M/T cells could use spike timing as a measure of input strength. Similar results have been reported recently for respiration-coupled $\mathrm{M} / \mathrm{T}$ cell activity in anesthetized, freely breathing mice (Margrie and Schaefer, 2003). The relationship between first AP latency and the number of APs evoked implies a possible role for spike timing in coding odor intensity. Indeed, we find that $\mathrm{M} / \mathrm{T}$ cells responded to stronger odors with more APs during each cycle and a shorter latency to the timing of the first spike. What mechanism underlies the change of first AP latency? One possibility is that the timing of ORN inputs to M/T cells is shifted earlier by stronger odors. In support of this hypothesis, the latency to the initial bursts of spikes in ORNs decreases with increases in odor intensity (Duchamp-Viret et al., 2000). However, this cannot account entirely for the latency changes of the $\mathrm{M} / \mathrm{T}$ cell spikes we observe because evoked EPSPs in some M/T cells did not necessarily show a significant decrease in latency in response to increasing odor intensity. Even for $\mathrm{M} / \mathrm{T}$ cells in which EPSP latencies decreased in response to stronger odors (Fig. 7), the latency shifts of the early APs were greater than those of the EPSPs. Rather, we believe that changes in the amplitude and slope of the underlying EPSPs are the major determinant in respiration-driven $\mathrm{M} / \mathrm{T}$ cell spike timing. In this scenario, the membrane potential of the $\mathrm{M} / \mathrm{T}$ cell simply reaches spike threshold earlier for stronger versus weaker odors.

Our results showing intensity-dependent changes in M/T cell action potential latency support the idea that spike timing during ongoing, rhythmic membrane activity can be used to encode features of olfactory stimuli (Hopfield, 1995; Laurent, 1999). However, several of our observations seem to contradict the hypothesis that individual spikes are important for information coding. First, many M/T cells fire APs spontaneously, and this activity may degrade the information contained by odor-evoked spikes. 
In addition, the latency of odor-evoked spikes can vary as much as $\sim 100$ msec even to the same odor concentration (Fig. 5). However, these issues reflecting the "noisiness" and response variability of individual $\mathrm{M} / \mathrm{T}$ cells can be minimized if information coding relies on the responses of a population of cells (Laurent, 1999). In this case, the average response of an ensemble of responding $\mathrm{M} / \mathrm{T}$ cells can also convey temporal information. In support of this view, we find that changes in odor intensity are also reflected in the timing of respiration-coupled IPSPs, which are attributable to lateral inhibition initiated by spikes from other $\mathrm{M} / \mathrm{T}$ cells that were excited by the odor. Although we cannot determine the role of spike timing in the coding of odor intensity in higher olfactory centers, we think it is likely that the intensitydependent latency shift of M/T cell APs contributes to the local processing of odor information in the olfactory bulb.

It is important to note that the effect on first AP latency may represent only a part of the ultimate strategy used in the coding of odor intensity. Our results also show that M/T cells fire more spikes in response to higher concentrations of odorants. It has also been shown that some M/T cells can change their response patterns from inhibition to excitation with increasing odor concentration (Wellis et al., 1989). Recent imaging studies have suggested that a spatial map of glomerular activity patterns may be used to encode odor information and that increasing odor intensity recruits more glomeruli (Rubin and Katz, 1999; Belluscio and Katz, 2001; Meister and Bonhoeffer, 2001) and thus more M/T cells. More recently, an imaging study has found that the glomeruli recruited by higher odorant concentrations have a longer latency to activation than those activated by lower concentrations (Spors and Grinvald, 2002). Furthermore, this study found oscillations in glomerular activity coupled to the respiratory rhythm even in the absence of applied odorants. This suggested that odor-intensity coding could involve both spatial and temporal components: intensity could be encoded by the recruitment of additional glomeruli and the overall latency relative to the respiration cycle and the neuronal activity coupled to it (Spors and Grinvald, 2002). These recent studies reinforce the notion that odor identity and intensity can be encoded by population responses of M/T cells. Our results of intensity-dependent changes in spike timing are likely to contribute to odor coding in the context of the spatial representation of odors in the bulb as well. For example, AP propagation in $\mathrm{M} / \mathrm{T}$ cell lateral dendrites can be gated by lateral inhibition (Xiong and Chen, 2002). Therefore, the timing of the first odor-evoked AP could be critical in determining the spatial extent of lateral interactions between $\mathrm{M} / \mathrm{T}$ cells.

In summary, we have characterized some of the basic synaptic events underlying the processing of olfactory information in the olfactory bulb. However, additional studies examining synaptic transmission in larger populations of olfactory bulb neurons will be essential to determine the relative contributions of temporal and spatial coding in the mammalian olfactory system.

\section{References}

Belluscio L, Katz LC (2001) Symmetry, stereotypy, and topography of odorant representations in mouse olfactory bulbs. J Neurosci 21:2113-2122.

Blanton MG, Lo Turco JJ, Kriegstein AR (1989) Whole cell recording from neurons in slices of reptilian and mammalian cerebral cortex. J Neurosci Methods 30:203-210.

Buck L, Axel R (1991) A novel multigene family may encode odorant receptors: a molecular basis for odor recognition. Cell 65:175-187.

Chaput M, Holley A (1980) Single unit responses of olfactory bulb neurones to odour presentation in awake rabbits. J Physiol (Paris) 76:551-558.
Chaput MA (2000) EOG responses in anesthetized freely breathing rats. Chem Senses 25:695-701.

Chen WR, Xiong W, Shepherd GM (2000) Analysis of relations between NMDA receptors and GABA release at olfactory bulb reciprocal synapses. Neuron 25:625-633.

Clements JD, Bekkers JM (1997) Detection of spontaneous synaptic events with an optimally scaled template. Biophys J 73:220-229.

Duchamp-Viret P, Duchamp A, Chaput MA (2000) Peripheral odor coding in the rat and frog: quality and intensity specification. J Neurosci 20:2383-2390.

Friedrich RW, Laurent G (2001) Dynamic optimization of odor representations by slow temporal patterning of mitral cell activity. Science 291:889-894.

Hamilton KA, Kauer JS (1989) Patterns of intracellular potentials in salamander mitral/tufted cells in response to odor stimulation. J Neurophysiol 62:609-625.

Harrison TA, Scott JW (1986) Olfactory bulb responses to odor stimulation: analysis of response pattern and intensity relationships. J Neurophysiol 56:1571-1589.

Hopfield JJ (1995) Pattern recognition computation using action potential timing for stimulus representation. Nature 376:33-36.

Imamura K, Mataga N, Mori K (1992) Coding of odor molecules by mitral/ tufted cells in rabbit olfactory bulb: I. Aliphatic compounds. J Neurophysiol 68:1986-2002.

Isaacson JS (2001) Mechanisms governing dendritic gamma-aminobutyric acid (GABA) release in the rat olfactory bulb. Proc Natl Acad Sci USA 98:337-342.

Isaacson JS, Strowbridge BW (1998) Olfactory reciprocal synapses: dendritic signaling in the CNS. Neuron 20:749-761.

Jahr CE, Nicoll RA (1980) Dendrodendritic inhibition: demonstration with intracellular recording. Science 207:1473-1475.

Kashiwadani H, Sasaki YF, Uchida N, Mori K (1999) Synchronized oscillatory discharges of mitral/tufted cells with different molecular receptive ranges in the rabbit olfactory bulb. J Neurophysiol 82:1786-1792.

Kauer JS (1974) Response patterns of amphibian olfactory bulb neurones to odour stimulation. J Physiol (Lond) 243:695-715.

Laurent G (1999) A systems perspective on early olfactory coding. Science 286:723-728.

Laurent G, Stopfer M, Friedrich RW, Rabinovich MI, Volkovskii A, Abarbanel HD (2001) Odor encoding as an active, dynamical process: experiments, computation, and theory. Annu Rev Neurosci 24:263-297.

Lei H, Christensen TA, Hildebrand JG (2002) Local inhibition modulates odor-evoked synchronization of glomerulus-specific output neurons. Nat Neurosci 5:557-565.

Luo M, Katz LC (2001) Response correlation maps of neurons in the Mammalian olfactory bulb. Neuron 32:1165-1179.

MacLeod K, Laurent G (1996) Distinct mechanisms for synchronization and temporal patterning of odor-encoding neural assemblies. Science 274:976-979.

Macrides F, Chorover SL (1972) Olfactory bulb units: activity correlated with inhalation cycles and odor quality. Science 175:84-87.

Mair RG (1982) Response properties of rat olfactory bulb neurones. J Physiol (Lond) 326:341-359.

Mair RG, Gesteland RC (1982) Response properties of mitral cells in the olfactory bulb of the neonatal rat. Neuroscience 7:3117-3125.

Malnic B, Hirono J, Sato T, Buck LB (1999) Combinatorial receptor codes for odors. Cell 96:713-723.

Margrie TW, Schaefer AT (2003) Theta oscillation coupled spike latencies yield computational vigour in a mammalian sensory system. J Physiol 546 2:363-374.

Margrie TW, Sakmann B, Urban NN (2001) Action potential propagation in mitral cell lateral dendrites is decremental and controls recurrent and lateral inhibition in the mammalian olfactory bulb. Proc Natl Acad Sci USA 98:319-324.

Meister M, Bonhoeffer T (2001) Tuning and topography in an odor map on the rat olfactory bulb. J Neurosci 21:1351-1360.

Meredith M (1986) Patterned response to odor in mammalian olfactory bulb: the influence of intensity. J Neurophysiol 56:572-597.

Mombaerts P, Wang F, Dulac C, Chao SK, Nemes A, Mendelsohn M, Edmondson J, Axel R (1996) Visualizing an olfactory sensory map. Cell 87:675-686. 
Mori K, Nagao H, Yoshihara Y (1999) The olfactory bulb: coding and processing of odor molecule information. Science 286:711-715.

Onoda N, Mori K (1980) Depth distribution of temporal firing patterns in olfactory bulb related to air-intake cycles. J Neurophysiol 44:29-39.

Ravel N, Caille D, Pager J (1987) A centrifugal respiratory modulation of olfactory bulb unit activity: a study on acute rat preparation. Exp Brain Res 65:623-628.

Rubin BD, Katz LC (1999) Optical imaging of odorant representations in the mammalian olfactory bulb. Neuron 23:499-511.

Schoppa NE, Kinzie JM, Sahara Y, Segerson TP, Westbrook GL (1998) Dendrodendritic inhibition in the olfactory bulb is driven by NMDA receptors. J Neurosci 18:6790-6802.

Shepherd GM (1998) The synaptic organization of the brain, Ed 4. New York: Oxford UP.

Sobel EC, Tank DW (1993) Timing of odor stimulation does not alter patterning of olfactory bulb unit activity in freely breathing rats. J Neurophysiol 69:1331-1337.
Spors H, Grinvald A (2002) Spatio-temporal dynamics of odor representations in the mammalian olfactory bulb. Neuron 34:301-315.

Uchida N, Takahashi YK, Tanifuji M, Mori K (2000) Odor maps in the mammalian olfactory bulb: domain organization and odorant structural features. Nat Neurosci 3:1035-1043.

Wachowiak M, Cohen LB (2001) Representation of odorants by receptor neuron input to the mouse olfactory bulb. Neuron 32:723-735.

Wellis DP, Scott JW (1990) Intracellular responses of identified rat olfactory bulb interneurons to electrical and odor stimulation. J Neurophysiol 64:932-947.

Wellis DP, Scott JW, Harrison TA (1989) Discrimination among odorants by single neurons of the rat olfactory bulb. J Neurophysiol 61: 1161-1177.

Xiong W, Chen WR (2002) Dynamic gating of spike propagation in the mitral cell lateral dendrites. Neuron 34:115-126.

Zufall F, Leinders-Zufall T (2000) The cellular and molecular basis of odor adaptation. Chem Senses 25:473-481. 